doi: $10.15503 /$ jecs2021.1.45.58

\title{
THEORETICAL BACKGROUND FOR A STRATEGY OF DEVELOPMENT OF CULTURAL LITERACY IN SCHOOLS
}

\author{
GIORGI KOBAKHIDZE \\ Academy of Education, Vytautas Magnus University, \\ K. Donelaičio str. 58, LT-44248 Kaunas, \\ the Republic of Lithuania \\ E-mail address: giorgi.kobakhidze@vdu.lt \\ ORCID: https://orcid.org/0000-0002-0018-4941
}

\begin{abstract}
Aim. Based on the analysis of two social-cultural cases (Lithuania and Georgia), the aim of the research is to reveal the necessity to create a strategy for the development of cultural literacy in schools; to examine the corpus of theory that deals with the concept of cultural literacy and based on the analysis of the latter to suggest a hypothesis for the development of cultural literacy.

Methods. The theoretical literature review (i.e., its relevance in academic discourse and international organisations as well as individual countries) has helped to establish the already existing definitions of the concept of cultural literacy, their interaction and to develop a new hypothesis to be tested for the development of cultural literacy in schools.

Results and conclusion. The literature review has shown that representatives of different theories offer different definitions of cultural literacy, although there is a common theoretical line on the basis of which I offer to the reader my own structure of cultural literacy development strategy. The analysis of historical and geographical contexts of Lithuania and Georgia has revealed that nowadays even small countries' society, with a dominant single nation, in some ways can be considered as a multicultural society. Schools in the said countries have become an intercultural place of learning, where reemigrants, migrants, ethnical minorities and locals are brought together. The analysis has led to the conclusion that taking into account modern challenges, the importance of the development of cultural literacy in schools is growing both for international organisations and for individual countries. The concept of cultural literacy is considered value-based knowledge, which comes as a response to the requirements of society's sustainable coexistence.

Originality. On the basis of the theoretical background of the cultural literacy concept within the hypothesis, the research has provided a new description of the process (development of cultural literacy in schools).
\end{abstract}

Key words: literacy, cultural literacy, cultural literacy development strategy 


\section{INTRODUCTION}

Tn today's global environment, with the increase in trends of global migration 1 and the emergence of new forms of cultural and national identity (hybrid, mixed identity), general education schools become an intercultural place of learning. The ongoing immigration and repatriation, country's ethnic minorities, geopolitical space with open borders (European Union) and temporary residence abroad result in the presence in school communities of schoolchildren with different cultural and national identity, different mindsets and approaches to certain phenomena. As a result of different expressions and development particularities of hybrid cultural and national identities, and taking into consideration the cultural school environment and the school's task to prepare the young ones to readily transition into a wider/multicultural society, it is recommended to apply context-appropriate strategies, where teachers and other members of the educational community perform the task of developing cultural literacy and cultural identity in students.

\section{THE RELEVANCE OF CULTURAL LITERACY IN THE GLOBAL WORLD}

The UNESCO World Report on Cultural Diversity (2009) states that the effects of globalisation (and growing urbanisation and migration) challenge the way we perceive culture and identity. In this sense, cultural diversity as well as the relationship between globalisation and cultural diversity are a far more complex phenomenon than it may seem at the beginning. As these are facts we must accept, it is vital to provide conditions, which would allow cultural diversity becoming a tool of assuring dialogue and peaceful coexistence as well as of sustainable and fruitful development (Investing in Cultural Diversity and Intercultural Dialogue: UNESCO world report, 2009).

If cultural diversity is not taken into account, education cannot fulfil its role of learning to live together. Consequently, the development of intercultural competencies that are conducive to dialogue between cultures and civilizations should be an educational priority. It calls for the training of teachers in the challenges of intercultural and inter-religious education, and presupposes the involvement of the larger community to help raise the profile of cultural diversity in educational practices, including in out-of-school activities (Investing in Cultural Diversity and Intercultural Dialogue: UNESCO world report, 2009, p. 254).

The Report also states that because cultural diversity cuts across a whole series of public-policy areas not obviously related to culture, UNESCO has a particular responsibility to assist Member States in the formulation of relevant policies in all its fields of competence (Investing in Cultural Diversity and Intercultural Dialogue: UNESCO world report, 2009).

The UNESCO World Report (Investing in Cultural Diversity and Intercultural Dialogue, 2009) focuses on cultural diversity related challenges: combat- 
ing cultural illiteracy; reconciling universalism and diversity; and supporting new forms of pluralism resulting from the assertion of multiple identities by individuals and groups. The Report insists that in a globalised world in which the contacts between cultures are expanding rapidly, it is necessary to combat the spread of cultural illiteracy. Indeed, the ability to accept cultural differences and agree with them unconditionally calls for intercultural competencies.

The UNESCO Survey on Intercultural Dialogue (2017) states that specific competencies are required to rely on the intercultural principles to promote tolerance, respect, dialogue and mutual understanding. The findings point out the crucial role of educational institutions in building and enhancing the resilience of societies, promoting citizen responsibility, inclusion and pluralism. According to the Report, people are not born with intercultural competencies, they acquire them through learning and life experience. This means that in the modern society the critical importance of human rights violation depends on our ability to acquire and demonstrate intercultural competencies.

This issue has been considered when updating Lietuvos Pradinio ir pagrindinio ugdymo bendrasias programos (2021) [The General Framework for Lithuanian Primary and Basic Education] as one of the generic competences that should be addressed in all the subjects of the cultural competence, which aims at the development of reasonable, open-minded, culture-oriented and creative personalities, active members of school, community and national cultural life, who are able to cherish and promote Lithuanian, European and global culture, build sustainable and responsible society, and who - through their values - are committed to the cultural continuity of their people and country, but remain open to other cultures and diverse ideas and are able to show cultural awareness of their behaviour.

At the EU level, the relevance of cultural literacy is emphasised in the call by EU Horizon Research Programme H2020, titled Cultural Literacy of Young Generations in Europe (CULT-COOP-03-2017). The programme holds cultural (national identity) diversity as one of Europe's most valuable assets. Aside from developing national identity, there is a goal to promote European identity and European culture (European cultural heritage and culture); therefore, such competencies as inter-cultural and mutual understanding and development gain importance. A key aspect of this programme is the relationship between formal and informal education and the environment that influences young people: family, communities, cultural background, media, virtual communities, etc. One project within the said EU framework Dialogue \& Argumentation for Cultural Literacy Learning in Schools believes that cultural literacy stems from combining individual competencies with cultural diversity and creating individual identity in a respectful social interaction with other people. Cultural literacy requires acknowledgement of differing views but it also refers to our metacognitive awareness of how our cultural relationships affect responses and feelings of others. DIALLS is mainly based on the assumption that the development of dialogue and argumentation skills will increase competencies of young people's cultural literacy. The project of common Europe has been 
consistently ongoing for 70 years and the economic and social environment created by Member States is undeniably multicultural, therefore, a further sustainable development of the EU community calls for inter-cultural teaching of young people and DIALLS (Dialogue and Argumentation for Cultural Literacy Learning in Schools) is part of this programme to overcome such challenges.

At national level, Member States, including Lithuania, are also multicultural to a certain extent: ethnic minorities, present in the country, cherish and foster their culture, there are constant developments of repatriation, people arrive from abroad and migrate within the EU territory. As a result, the intercultural dialogue and the development of cultural literacy at schools play an increasingly important role in order to assure the transition of young people into a multicultural society and their self-identification of beliefs and views as well as the recognition of other cultures and establishing a dialogue with them.

\section{DEVELOPING THE CONCEPT OF CULTURAL LITERACY}

The concept of cultural literacy has been the object of discussion in the research society since the 1980s. The concept of cultural literacy and literacy in general, used by the American scholar Erik Hirsch (1983) have been moved from an integral level of reading, writing, and numeracy to a different level of value-based knowledge. Whereas in underdeveloped countries literacy in its traditional sense remains a challenge to education, in developed countries, multicultural places and geopolitical phenomena such as the European Union, the concept of cultural literacy is a response to the requirements of society's sustainable coexistence.

Hirsch (1983) believes that without an appropriate and common knowledge people cannot understand the information put forward in the media, and refers to this canonical common knowledge as cultural literacy. Understanding the information published by the media is interpreted as an essential tool of the country's taking part in public processes. Hirsch states that this is a translingual knowledge, based on interdependent linguistic knowledge. The US researcher argues that this phenomenon is well known to foreign language teachers, but exactly the same process is at play when one learns about the national culture and in one's mother tongue. According to the researcher, schools usually take into account acculturation, i.e., the common knowledge that the readers should have. This knowledge consists of education-controlled topics, and its transfer is one of the country's goals for culture creation. To this end, Hirsch came up with a cultural literacy dictionary, which included the most important concepts, names, phrases and events that, in his opinion, students after graduation should know (to some extent this could be compared to a national cultural literacy encyclopaedia).

The Hirsch approach has met some criticism. One of his critics Leila Christenbury (1989) believes that understanding cultural literacy as the knowledge of dominant culture, and requiring students and society to share a common 
and specific knowledge as a cornerstone is an elitist approach; and argues that students should develop critical reading skills rather than recognise a set of established concepts from literary texts. This criticism of Hirsch's cultural literacy approach is based on his priority of the definition of words over the meaning of text.

Harry S. Broudy (1990) also questions the importance of knowing names and events in cultural literacy. He believes cultural literacy is a deeper understanding (of human ideas and ideals) than a vague associative memory of terms. He also focuses on the selection of classical literature, which is highly ranked in Hirsch's dictionary, and claims that even though the knowledge of classics and education are linked, cultural literacy goes way beyond classical literature and Hirsch's dictionary. He compares cultural literacy with the study of humanism and argues that if works of classical literature contribute to the construction of cultural literacy, they should be taught together with intellectual, moral and aesthetic dimensions.

Chris M. Anson (1988) also points out that the concept of cultural literacy leaves out the idea that an educated person should not only be able to identify facts but also should have the ability to understand why a certain event plays an important cultural role. He also suggests teaching cultural literacy in a way that would allow students to understand the essence and epistemology of the texts they read, in order to focus not on what you study but how you study.

Alan Simpson (1991) considers Hirsch's theory as descriptive because it refers to what society should know rather than what its values should be. He states that in anthropologic and social definitions culture is a far more complex phenomenon that includes customs, rituals, internal relationships, linguistic habits, political and economic system, religious beliefs and rejects the idea of putting all of this in a dictionary.

Representative of critical theory Paulo Freire (1970) criticises the concept of literacy. He argues that teaching literacy is a cultural act setting one free; a cognitive act through which a student with the help of the dialogue with the teacher gets to know the role of the learning subject. Considering literacy as a cognitive, creative and political act, an ability to read the world and the word, he argues that texts are inconceivable without context.

Following the ideas of Freire, Peter McLaren (1988) argues that texts are products supplying information to the interests of dominating social and cultural groups. He argues that Hirsch's approach overlooks the disregard of the link between power and knowledge and states that teaching the selected works does not consider the understanding of the weight of the ideological dimensions of these works, the understanding that allows us to know the interests and values of the society those works were created in. He complements the concept of critical literacy with decoding of ideological dimensions of texts, institutions, social practice and such cultural forms as television and movies, and all of this reveals their selective interests. At the basis of critical literacy there is the creation of a citizen-critic, who could contribute to a more just and democratic society. He also points out the challenges of literacy in gender, 
racial, social and economic contexts. A significant focus is placed on language skills. He believes critical literacy to be linked to the ability to include language in a public discourse, where an empowered person is able to take a critical part in social, political and ethnic aspects of everyday life.

It must be noted that the way representatives of the critical theory interpret Hirsch's approach as elitism and oppression, focusing on this aspect and dividing social groups within the society, is rather deconstructive.

When criticising Hirsch's theory, Richard Paul (1991) focuses more on the development of critical reading skills. He argues that critically literate readers should be able to distinguish between sources and meanings of concepts they use in conclusions and most importantly - to understand the logic behind them. A critically literate reader is able to tell cultural associations from empirical facts, data from interpretation, events from conclusions, beliefs from knowledge, conviction from stubbornness, criticising from criticism, conversation from gossip, mastery from domination. He proposes four categories that a critical reader should verify: 1 ) the source of ideas or concepts, 2) the substructure of ideas or concepts, 3) the implications or consequences of the ideas or concepts and 4) similarities and differences in the idea relationships. He calls for the separation of information and knowledge and points out the complexity of social and cultural contexts. He believes that when reading a text, the construction is frequently interpreted individually, depending on prejudice, hatred, fears, stereotypes, cartoons and imagination.

In their third book on cultural literacy, Hirsch, Joseph F. Kett and James Trefil (2002) equate the concept of cultural literacy to national culture as criticism and believe that the concept prioritises national culture as a means of national society's unity: 'national communities are brought together not only by political institutions and law but by common values, allusions and language;' and point out that common knowledge of things is key to internal communication of a nation. In response to the threat of nationalism and critical theorists, they argue that love for one's country or patriotism is a different feeling than nationalism. Nationalism requires a rival and opponent, whereas patriotism refers to love without opposition. In their opinion, American patriotism is based on common knowledge, beliefs, loyalty and values, such as inclusion, tolerance and respect for other religions and cultures. He agrees with the critics and regards his concept of cultural literacy, even if necessary, to the society, not as deep knowledge but as a way to better learn about things.

Liisa Salo-Lee (2007) uses the concept of cultural literacy as intercultural competence, as the most important goal of education globally. He points out the global migration as the foundation of multicultural society and demands all those involved to have intercultural competencies, intercultural interaction; and defines cultural literacy as an ability to read, understand and find significant aspects in different cultures and an opportunity to assess, compare and decode different cultures intertwined in a single space.

From an anthropological perspective, Steven F. Arvizu and Marietta Saravia-Shore (2017) in the concept of intercultural literacy include not only cul- 
tural literacy (knowing and understanding your own national culture) but also understanding the interaction of other cultures, their values, institutions, metaphors and symbols as a means of intercultural communication. In this regard, intercultural literacy enables meaningful communication between cultures as well as nations. The US example also considers intercultural communication a necessity for all teachers because the US school system promotes the development of multicultural student groups, including immigrants, and preparation of students for the future with a stronger interdependency, economic relationship and communication skills based on multicultural interaction. The author believes that intercultural literacy means that teachers as well as students should register people, problems, challenges and solutions according to different cultural orientations; respect human rights and way of life of different people and groups and engage in a meaningful communication with people of other cultures. An intercultural approach provides teachers with methods and cultural competencies such as empathy, teaching tools, perception, observation, interpretation and understanding of values, parent and student expectations and leads to the emergence of culture-based interaction patterns between adults and children or between children. A key aspect is the employment of ethnographic teaching methods in intercultural environments and the following determination of the students' cultural background to facilitate learning. The author also deems Hirsch's concept of cultural literacy as limited and vague considering the anthropological aspect.

In the process of acquiring cultural literacy, Bernardo Ferdman (1990) points out the aspect of cultural identity, which is formed by means of selfperception in the relationship with a native ethnic group and a larger society. He distinguishes between cultural literacy in a homogenous society and in a pluralistic society. The homogenous society has the same range of customs over time and in space, whereas in pluralistic society, it is the one who knows ways and boundaries of different cultures that is considered literate. He also criticises Hirsch's theory for lacking concepts and ideas of learning about different meanings (concepts and ideas are considered to have an absolute meaning). Knowing facts is not enough, it is necessary to develop skills which would allow discovering and deciding what information and values are transferred within one's cultural identity.

Brian Street (2003) focuses on events and processes in literacy and discusses the autonomy of literacy and ideological concepts. In his opinion, autonomy links literacy with people's well-being through their talents, whereas ideological literacy is viewed as a social practice. Not only is literacy a technical and neutral skill, it is also a form of social practice. It is always intertwined with a socially constructed epistemological principle. Literacy practice refers to a broader cultural conception about certain ways of thinking, reading and writing in the context of culture. Therefore, both methodological and empirical levels raise the question of how to define the transition from the observation of literacy events to the conceptualisation of literacy practice. The concept of literacy practice falls at a high level of abstraction and defines behaviour and 
social and cultural conceptions, which give meaning to reading and (or) writing. Street (2003) believes literacy is based on ideological and political assumptions, which hinders ethnographical research on literacy in all possible contexts (students come to class with different backgrounds and it is impossible to know all of them). Street's theory does not require an ethnographic definition of literacy; he argues that instead of analysing literacy researchers should analyse literacy's social practice.

Definitions of cultural literacy by different authors offer a set of different competencies and abilities. Elena Shliakhovchuk (2019) proposes the following dimensions of cultural literacy: cultural mindfulness (cultural self-awareness, local culture awareness, intercultural sensitivity, empathy), critical thinking, curiosity, and being a Change Agent Leader (influencer). Cultural literacy is the ability to recognise, discover, use and modify a variety of possible cultural artefacts, including texts and other instruments of media that have an effect on our cultural existence. It is an approach that refers to artefacts that highlight communication, compare and criticise and rally ideas through interdisciplinary and international collaboration (Caball, 2013).

The social-constructivist perspective $(\mathrm{Au}, 1998)$ examines seven aspects of cultural literacy that should be included when researching literacy: a) the goal of instruction, b) the role of home language, c) instructional material, d) classroom management and interaction with students, e) relationship to the community, f) instructional methods, and (g) assessment.

Researchers Victoria Cook and Fiona Maine (2019), who take part in the DIALLS project, with reference to cultural literacy focus on the links between cultural awareness, cultural knowledge and cultural expressions as well as those between cultural identity and cultural values.

Maine, Cook and Tuuli Lähdesmäki (2019) emphasise individual's disposition and competence to encounter cultural differences and to elaborate one's own identity in respectful social interaction with other people.

With this reconceptualization, we seek to emphasize the very idea of intercultural dialogue. If cultural literacy necessarily includes notions of the social, then it is about more than individuals and their relationship to culture, but also how they then engage with each other. This centralizes social interaction as key to understanding one's own cultural identity and acknowledging cultural differences. To move from a monologic model of cultural literacy to a dialogic one considers how people are disposed to engage together through social interaction with their cultural identities, heritages and values, creating fluid and changing cultural practices that celebrate difference and alternative perspectives (Maine, Cook, \& Lähdesmäki, 2019, p. 388).

\section{ASSUMPTIONS FOR A CULTURAL LITERACY DEVELOPMENT STRATEGY}

On the basis of the literature reviewed, I suggest an assumption for a cultural literacy development strategy that would consider the current develop- 
ment practice and define its purpose and implementation methods.

In this respect, the development of cultural literacy has two intertwined realities:

- becoming open-minded (for students) through value-based education from textbooks (history, literature, religion, ethics, civil awareness) and learning environment;

- knowledge and identification of cultures (for teachers), which facilitates learning in multicultural environment (in alignment with hermeneutic teaching methods).

The development of cultural literacy is based on two-tier interdependent purposes:

- the purpose of reading tradition in developing cultural literacy (critical reading). In this respect, the concept of media literacy should be analysed as part of modern learning;

- developing cultural literacy as a human quality and set of competencies has the social purpose of consolidating society in a multicultural environment (both Lithuania and Georgia have ethnic minorities that protect and cherish their culture; Lithuania experiences constant repatriation and immigration of economic migrants from third countries, amidst a growing internal migration within the EU).

To be able to identify these processes is key in language policy and education (the level of knowledge).

\section{STUDENT AND TEACHER INTERACTION \\ IN THE PROCESS OF DEVELOPING CULTURAL LITERACY: BECOMING OPEN MINDED, LEARNING AND KNOWING DIFFERENT CULTURES}

The design of school curriculum should be based on cultural literacy dimensions that ensure the instruction of values inherent in the country's society, and formed over the years, as well as of general humane views. In order not to be constrained by habits, customs, narratives and artefacts formed over time and in space, they should be introduced to general humane values. In this case, education should be based on imparting values rather than specific cultures and their differences. This is not to say that school textbooks (teaching literature, history, art) have not previously addressed such subjects, but adopting this idea as a general direction would be a criterion for developing and selecting textbooks in the future. These subjects (values) by textbook pieces should be known to teachers so that they can be thoroughly and ethically addressed. The material used for graduation exams should also feature selected sections of cultural literacy. This, of course, includes the school curriculum chosen in alignment with the cultural literacy strategy.

Some definitions of cultural literacy focus on the extensive knowledge of cultures resulting from the ability to communicate with others. Such defini- 
tion is more akin to the concepts of multiculturalism and interculturalism. According to Arvizu (Arvizu \& Saravia-Shore, 2017), in order to attain intercultural literacy, it is necessary to conceptualize the content of education in alignment with anthropological literature, to investigate the relationship between schools and society, to design staff and training programmes and their assessment based on ethnographic methods. In my opinion, instructing specific cultures at school is an impossible goal and the focus should be placed on value-based learning that aims at preparing students for society life. The research of students cannot be the goal of cultural literacy as they need to be educated rather than researched. Teachers cannot possibly know all the cultures and languages of possible students but should show interest and open-mindedness.

From a social-constructivist perspective (Au, 1998), multicultural classrooms may be subject to a certain level of teacher's inequality in a given educational situation that depends on how the teacher perceives their own cultural identity and that of the students'. He believes that researchers should be aware of how their cultural identity effects their literacy and literacy development. Following the main constructivist theory, in order to express themselves and to succeed in society, students should first acquire literacy skills. The theory implies that an individual does not need to care about the qualification more than he has to care about transformative literacy opportunities. According to Kathryn H. Au's social-constructivist theory, teachers with multi-tiered constructivist orientation and using multicultural literature comprehend that it is not only the selection of books that counts but also the teaching method. Teachers should resort to multicultural literature to encourage a critical analysis of social and historical problems and provide students with more opportunities to solve social problems. Students with different backgrounds are thought to improve their literacy skills, if teachers can assure a culturally-responsive management and communication in class. This fact relates to the explanation of cultural differences and explanation motives in the teaching process as well as cultural/linguistic inclusion. Modern teaching methods also emphasise the role of the hermeneutic teacher; here the meaning of hermeneutics (interpretation), as a definition of a philosophical theory, refers to the explanation of different cultural and social phenomena (Duoblienè, 2011).

\section{THE PURPOSE OF SOCIETY CONSOLIDATION AND PRODUCTION OF CRITICAL READERS (CITIZENS)}

Hirsch et al. (Hirsch, Kett, \& Trefil, 2002) believe that nation's literacy and the knowledge received at school are interrelated. Reviewing the content of learning paves the way for cultural and ideological values represented in that content. Literacy, according to them, is not only a skill, but also a political decision. The decision to build a literate society is a value that should be appreciated and given priority. 
In my opinion, a culturally literate individual should be able to identify the mood, idea and context in a given text. Media literacy can be analysed as part of education that can be divided into targeted and automated learning. Targeted receipt of information is considered a learning process, in which students are required to have certain competencies. Individuals do not always realise they are being educated and their consciousness is constructed through media culture, which is often invisible and occurs in the unconscious (Kellner \& Share, 2005).

Sonia Livingstone (2004) argues that media literacy is the ability to access multiple contexts, and to analyse, assess and create information messages. This means being not only the consumers of the information market but also citizens. Technological, media and societal changes call for the development of critical media literacy to enable learners and citizens to adequately read media messages and produce media to actively take part in a democratic society (Kellner \& Share, 2007).

The critical theory (Kellner \& Share, 2005) considers media to be based on the fact that all information messages are construed in the same way in all forms of media communication ( $\mathrm{tv}$ programmes, internet, advertising, internet discussions, e-mails, messages, blogs, forums, books). Such a situation calls for a critical approach to understand how media constructs meaning, influences and shapes the audience and imposes its messages and values.

\section{LANGUAGE}

Knowing the language is critical for the entire society: repatriated emigrants, migrants, natives, ethnical minorities for full text comprehension and engagement. As far as social practice is concerned, language consists of material and social reality, which informs about the language codes and user subjectivity. Language provides us with tools to create a meaning from a universe of undefined signs (McLaren, 1988).

\section{CASES OF LITHUANIA AND GEORGIA}

In the case of Georgia, Edisher Japharidze (2017) distinguishes three waves of emigration: the first two saw the migration of political elite due to the Soviet occupation in 1921-1930 and in 1939-1945. During the Soviet occupation, Nino Otkhozoria (2016) also points out the repressive emigration of Georgians in other countries annexed by the Soviet Union. The third wave happened in 1991-1992 as a result of territories lost in the war with Russia and the difficult political and social situation in the aftermath of the civil war. He also highlights the social-economic emigration phenomenon in 2001, which was further partially fuelled by the visa-free regime with the EU Member States, introduced in 2017 (the Georgians as economic emigrants mostly leave for France, Germany, Sweden, Greece, Italy and Spain). 
The Lithuanian Emigration Institute under Vytautas Magnus University also distinguishes three migration waves in the history of Lithuania. The first two were caused by economic emigration at the turn of the $19^{\text {th }}-20^{\text {th }}$ century (the so called grynoriai). The second wave of emigration from the Republic of Lithuanian took place in 1920-1940. The third wave refers to political refugees who left Lithuania at the end of World War II, when Lithuania was occupied by the Soviet Union (the so called dipukai (displaced persons).

Modern migration patterns should also be mentioned. Modern migration started as social-economic migration after the restoration of Independence and to some extent is still happening. According to the Statistics Office in Georgia and Lithuania, there is an increasing trend of migrants returning home: in 2019 there were 40,000 immigrants in Lithuania, where the total population is 2.79 million. It is the highest number of immigrants since the restoration of Independence. More than half of them (50.9\%) are Lithuanian citizens returning to their motherland to live. In 2019, out of 96,800 immigrants to Georgia (total population: 3.72 million) 56.3\% were Georgian. These happenings pose new challenges to Georgian and Lithuanian societies and bring out multiculturalism, which must be taken into account in the learning process.

It is worth mentioning that even though Georgia and Lithuania are rather homogenous countries, other nationalities comprise about $15 \%$ of their total populations. In Lithuania, the majority of them are Polish (5.6\%) and Russian (4.8\%). In Georgia Azerbaijanis make up $6.3 \%$ of the population and Armenians amount to $4.8 \%$. These numbers are a testimony to a possible multicultural environment at schools that will require the development of cultural literacy.

Given the structure of society on a global scale, in international organisations (UN, EU) and multi-ethnic and multicultural countries such as USA, Canada, etc. issues of cultural literacy and identity development are widely discussed in research literature, but small countries with a historically dominant single nation need to be as prepared for the challenges presented by recently increasing repatriation trends, children returning home with different cultural backgrounds, presence of ethnical minorities and shared geopolitical spaces - all of which constitute the foundation of a multicultural society. This offers an opportunity to examine theories of cultural literacy in different historical and geographical contexts.

This subject does not deal with the relationship between citizenship and nationality as it is the question of personal feelings, but the country's language, history and knowledge of the values existing in a society are a priority of one's life. All the more so as we live in an era of rule of law, where education policy is a key prerogative in order to establish and improve the harmonious state. The development of cultural literacy is not the oppression of ethnical minorities and supremacy of the majority, as argued by the critical theory representatives. Furthermore, the development of cultural literacy promotes the existence of humane values in cultural dialogue and prevents the suppression of cultural co-existence in the multicultural environment. 
As small countries, Georgia and Lithuania have always had their societal vitality supported by their culture (in the broadest sense of the word: language, religion and territory). But what can be observed as well is a peaceful and dialogue-based coexistence, which helps other nations preserve their cultural specifics.

Although education-related documents in Georgia and Lithuania emphasise the role of cultural teaching, an important question remains: which aspects should be prioritised in the implementation of cultural literacy development strategy, taking into consideration education principles established in each country. In 2020, these aspects of education content are discussed by Lithuanian education researchers and practitioners in consultations over topics of general curricula and integration of cultural competencies.

\section{CONCLUSION}

In the era of globalisation, the development of cultural literacy around the world is becoming one of the most pressing educational issues, as evidenced by the UN and EU documentation. The concepts of cultural literacy and literacy skills have shifted from an integral level of reading, writing, and numeracy to a different level of value-based knowledge. In developed or multicultural countries and geopolitical phenomena, such as the European Union, the concept of cultural literacy is a response to the requirements of society's sustainable coexistence. Lithuania and Georgia are no exceptions with present circumstances determining the implementation of a respective cultural literacy strategy defined by the priorities of education curriculum. All of this emphasises the key role the development of cultural literacy plays in schools and the need for school communities to adopt an agreement-based, coherent cultural literacy development strategy.

\section{REFERENCES}

[1] Anson, C. (1988). Book Lists, Cultural Literacy, and the Stagnation of Discourse. The English Journal, 77(2), 14-18. doi:10.2307/819507.

[2] Arvizu, S. F., \& Saravia-Shore, M. (Eds.). (2017). Cross-cultural literacy: Ethnographies of communication in multiethnic classrooms. London: Routledge.

[3] Au, K. H. (1998). Social constructivism and the school literacy learning of students of diverse backgrounds. Journal of literacy research, 30(2), 297-319.

[4] Broudy, H. (1990). Cultural Literacy and General Education. Journal of Aesthetic Education, 24(1), 7-16. doi:10.2307/3332851.

[5] Caball, M., Fortunati, L., Irzik S., Kelleher M., Koleva D., Landfester U., Rojola L., \& Segal N. (2013). What are Literacy and Cultural Studies. Cultural Literacy in Europe Today, 48, 4.

[6] Christenbury, L. (1989). Cultural Literacy: A Terrible Idea Whose Time Has Come. The English Journal, 78(1), 14-17. doi:10.2307/817980.

[7] Cook, V., \& Maine, F. (2019). Dialogic teaching: Using wordless texts to develop children's cultural literacy learning. Profession, 18, 19.

[8] Duoblienė, L. (2011). Ideologizuotos švietimo kaitos teritorijos [Ideological Territories of Education Change]. Vilnius: Vilnius University Press. 
[9] Ferdman, B. (1990). Literacy and cultural identity. Harvard educational review, 60(2), 181-205.

[10] Freire, P. (1970). The adult literacy process as cultural action for freedom. Harvard educational review, 40(2), 205-225.

[11] Hirsch, E. (1983). Cultural Literacy. The American Scholar, 52(2), 159-169. Retrieved May 16, 2020, from www.jstor.org/stable/41211231

[12] Hirsch, E. D., Kett, J. F., \& Trefil, J. S. (2002). The new dictionary of cultural literacy. New York: Houghton Mifflin Harcourt.

[13] Investing in cultural diversity and intercultural dialogue: UNESCO world report. (2009). Retrieved August 18, 2020, from: https:/ / unesdoc.unesco.org/ark:/48223/pf0000185202/

[14] Japharidze, E. (2017) History of the Georgian Political in Emigration in XIX-XX Centuries. Business-Engineering, 1-2, 223-231.

[15] Kellner, D., \& Share, J. (2005). Toward critical media literacy: Core concepts, debates, organizations, and policy. Discourse: Studies in the cultural politics of education, 26(3), 369-386.

[16] Kellner, D., \& Share, J. (2007). Critical media literacy, democracy, and the reconstruction of education. In: D. Macedo, \& S.R. Steinberg (Eds.), Media literacy: A reader (pp. 3-23). New York: Peter Lang Publishing.

[17] Lietuvos Pradinio ir pagrindinio ugdymo bendrasias programos. (2021) [Lithuanian Primary and Basic Education General Programs]. Retrieved August 23, 2020, from: https://www. mokykla2030.1t/kompetenciju-ir-vaiko-raidos-aprasai/

[18] Livingstone, S. (2004). Media literacy and the challenge of new information and communication technologies. The communication review, 7(1), 3-14.

[19] Maine, F., Cook, V., \& Lähdesmäki, T. (2019). Reconceptualizing cultural literacy as a dialogic practice. London Review of Education, 17(3), 383-392.

[20] McLaren, P. (1988). Culture or canon? Critical pedagogy and the politics of literacy. Harvard Educational Review, 58(2), 213-235.

[21] Otkhozoria N. (2018) Labor Migration From Georgia: Risks and Challenges. Proceedings, N2, 189-198.

[22] Paul, R. W. (1991). Critical and cultural literacy: Where E. D. Hirsch goes wrong. Critical Thinking: Focus on Social and Cultural Inquiry. Retrieved June 5, 2020, from: https://eric. ed.gov/?id=ED338557

[23] Salo-Lee, L. (2007). Towards cultural literacy. Education for global responsibility - Finnish perspectives, 31, 73-82.

[24] Shliakhovchuk, E. (2019). After cultural literacy: new models of intercultural competency for life and work in a VUCA world. Educational Review, 73(2), 1-22.

[25] Simpson, A. (1991). The Uses of "Cultural Literacy": A British View. Journal of Aesthetic Education, 25(4), 65-73. doi:10.2307/3332904.

[26] Street, B. (2003). What's "new" in New Literacy Studies? Critical approaches to literacy in theory and practice. Current issues in comparative education, 5(2), 77-91. doi: 10.1080/00131911.2019.1566211.

[27] UNESCO Survey on Intercultural Dialogue 2017: Analysis of Findings (2018). Retrieved August 2, 2020, from: http://uis.unesco.org/en/news/unesco-survey-intercultural-dialogue 